\title{
CARLOS MOLINERO Y SU INTERPRETACIÓN FÍLMICA DE LA OBRA TEATRAL SALVAJES, DE JOSÉ LUIS ALONSO DE SANTOS
}

\author{
Francisco Gutiérrez Carbajo
}

Universidad Nacional de Educación a Distancia

Los discursos fílmicos actuales no parecen confirmar las predicciones de los profetas de la postmodernidad ni aun el caso de películas como Salvajes, de Carlos Molinero, en la que se apuesta de forma decidida por reflexividad y en la que el espacio, que se nos brindaba como espectadores en la narrativa cinematográfica clásica, es sustituido por una representación reflexiva, abductiva, interpretativa y antiépica.

El recurso a la reflexibilidad cinematográfica, que abarca desde la «construcción en abismo» de Fellini hasta la doble ficción en algunas películas de Woody Allen, está empleado en la obra de Molinero con gran habilidad.

Como otros realizadores jóvenes, Carlos Molinero - intentando escapar del agujero wittgensteiniano- construye un discurso narrativo fílmico, que podría enmarcarse teórica y prácticamente en los territorios del neopragmatismo de Rorty. En Salvajes —al igual que en otras películas 
de nuestros días- estamos asistiendo a la construcción de un nuevo estatuto de la imagen, que suplanta al viejo representacionismo mimético y autorial. El hecho de que alguna crítica no haya visto el film desde esta perspectiva ha suscitado - como por otra parte no es infrecuente en el caso de las transposiciones- una polémica sobre el grado de acierto o desacierto en la traducción fílmica del discurso teatral.

El realizador de Salvajes, más que una traducción, lleva a cabo una interpretación de la obra teatral homónima de Alonso de Santos (2001), en la que, como ya resulta habitual en el dramaturgo vallisoletano, la realidad —incluso la que parece más próxima y cotidiana — entraña siempre múltiples pliegues, de los cuales sólo algunos emergen en una primera instancia perceptiva.

Estas diversas capas de la realidad y sus variados y ricos tratamientos han sido estudiados, entre otros, por Andrés Amorós (1992 y 1995), Miguel Medina Vicario (1994), César Oliva (1989 y 2001), Cristina Santolaria (1995), José Romera Castillo (2002) y Margarita Piñero (2001).

Para la interpretación de una adaptación tan singular, la investigación analítica de la morfología relacional entre estructuras cinematográficas y estructuras literarias (Bruneta, 1970), así como la de los principios de conmutación y traducción intersemiótica (verbal-icónica-verbal), puede partir de los presupuestos de los formalistas rusos, de los análisis semiológicos y de las investigaciones pragmáticas (Bruneta, 1987: 23), así como de la teorías del neopragmatismo rortyano. Aunque en este análisis no aplicaremos exhaustivamente ninguna de estas formulaciones, las tendremos en cuenta, sin embargo, como algunos de nuestros referentes.

Entre los mensajes pragmáticos, al realizador cinematográfico le interesa resaltar especialmente los de la inmigración y el racismo que no tenían esa densidad semántica en la obra teatral, centrada sobre todo en la violencia.

Carlos Molinero logra materializar en imágenes la definición que de estos conceptos ya formuló Albert Memmi como «la asignación final y generalizada de los valores de diferencias reales o imaginadas, en beneficio del acusador y en perjuicio de la víctima para justificar la agresión y el privilegio del primero» (Memmi, 1968: 186).

No importa que el dominador o los dominadores sean en este caso tan marginales como los dominados. Carlos Molinero quiere subrayar el 
papel del agresor, revelando lo que tiene de estereotipo, para a continuación deconstruir precisamente esa imagen estereotipada. Guillermo y Raúl - Mario y Raúl en la obra teatral-, como pertenecientes a una banda de skin heads, son ciertamente representantes de unos tipos reales, pero que en la transposición cinematográfica se erigen en constructos, en categorías narrativas, como el senegalés Omar, y como el resto de las que integran el discurso fílmico. Esa postura de distanciamiento y a la vez de compromiso le evita caer en maniqueísmos, en los que a veces se incurre en el tratamiento de estos delicados asuntos. A pesar de ello, en el film Salvajes aparecen explícitos los ritos y las conductas antisociales de los violentos.

Los racistas, como Guillermo y Raúl, fundamentan a veces su comportamiento no sólo en el odio al otro, sino en el miedo al otro. Eso no justifica sus acciones, pero puede contribuir a explicar sus componentes narcisistas, viles y despreciables.

Alonso de Santos, que, como se ha señalado, redefine en escena lo absurdo de estas formas de proceder, tiene buen cuidado en explicitar, por boca de los propios personajes, que tales conductas están basadas en configuraciones degradadas del individuo. Para el racista, los responsables de todos los males son los que vienen desde fuera a desestructurar unos usos sociales establecidos. El dramaturgo lo sintetiza muy gráficamente en las palabras que Raúl le espeta a Berta: «Si no viniera a aquí a joder toda esa gentuza, los moros, los negros y su puta madre...» (Alonso de Santos, 2001: 149). El skinhead intenta justificar su actividad, pero hasta el propio Comisario no encuentra explicación a tales hechos: «¿Cree de verdad que un pobre negro, que vive de vender tabaco en el metro, se va a atrever a meterse con una banda de vándalos como ésos?» (Alonso de Santos, 2001: 157).

Para el racista, ningún pueblo que no sea el suyo, merece atención ni respeto: «Esto lo hacen ratas los chinos que son unos cabronazos. Sí, es verdad. Y a los que se mueren de ellos, los deshacen en trocitos... y ya tienen cerdo agridulce. $\mathrm{Y}$ el pasaporte se lo dan a otro, y como son todos iguales, se viene otro chino a joder aquí» (Alonso de Santos, 2001: 187).

Para completar este mapa marcado por la diferencia, el individuo que está en la cama con Bea, cuando llega Berta, es un sudamericano, un cliente del club de alterne Siglo XX, en el que trabaja la sobrina.

Tampoco quedan bien parados los representantes del «honor patrio», pero ya se encarga de aclarar el representante del orden que se trata de «ván- 
dalos», es decir, de descendientes de aquellos bárbaros, que, como ha señalado César Oliva (Alonso de Santos, 2001: 157), procedentes de la Germania, invadieron la Península Ibérica. No nos detendremos en elucidar en este caso las posibles interpretaciones de la metáfora. Interesa quizá más transcribir las interrogaciones del propio comisario: «Muchas veces a lo largo de estos años, lidiando con gentes de todo tipo, me he preguntado cómo es posible que existan personas que nazcan así...». A Berta esta frase le parece terrible y se apresta a aclarar que nadie nace así: propiciamos esos comportamientos los demás, «nosotros, los que nos creemos buenos y honrados, y cerramos nuestra puerta o pasamos a su lado sin ayudarles...».

En medio de la tragedia siempre hay sitio en las obras de José Luis Alonso de Santos para el amor, e incluso para la utopía. Es el punto de luz en las tinieblas.

El Comisario y Berta, en las condiciones más adversas, son capaces de mantener una relación de adolescentes e incluso, al final, de formular un planteamiento utópico, no ajeno al motivo mítico del viaje.

La experiencia amorosa, aun reconociendo implícitamente su función como uno de los motores de la vida, es enjuiciada desde esa mirada tamizada por el relativismo y por cierto escepticismo existencial del dramaturgo. Si las aventuras del amor —incluso las más desgarradoras- están siempre amenazadas por el destino de la evanescencia, la que viven Berta y el Comisario en Salvajes está alimentada ya desde el principio por el signo de lo transitorio. A medida que se avanza hacia el final, nos vamos acomodando inexorablemente a los ciclos de la naturaleza, en los que cada cosa que tiene su inicio, conoce también su acabamiento. La fragilidad y vulnerabilidad resultan paradójicamente más patentes en los seres vivos, aunque sabemos que un día también se extinguirán los minerales y las rocas. Los clásicos se fijaron ya en la fugacidad de la naturaleza de la rosa; Alonso de Santos, representa metafóricamente en los geranios de la casa de Berta los afectos que primero deposita en ellos la mujer y que también terminará proyectando el Comisario. En el film de Molinero, Berta ejerce su función de enfermera en el Ambulatorio, y en ese espacio sitúa el realizador las plantas, portadoras — como en la obra de teatro- no sólo de significados designativos, sino también emotivos y expresivos (Morris, 1946: 24).

En contraste con el rostro feroz de la violencia, esos elementos representan la que puede considerarse la cara amable de la vida, la que alimenta la utopía. 
En otra ocasión (Gutiérrez Carbajo, 2001 y 2003) he observado cómo mi interpretación difiere de aquéllas que encuentran en las obras de Alonso de Santos una presencia dominante de elementos costumbristas. En Salvajes y en otras piezas, sin embargo, la realidad aparencial y fenomémica es sólo una de sus múltiples capas y no la más importante, incluso en el sentido que Heidegger descubre en la palabra phainomenon, como aquello que se muestra a sí mismo.

Alonso de Santos, que también es psicólogo, sabe que nuestra imprevisibilidad tiene mucho que ver con nuestra complejidad como seres humanos, y que todo o nada puede ser esperable porque casi todo o nada es capaz de transformar nuestras vidas o dejarnos aparentemente como estamos. Por eso, entre los diversos calificativos aplicados a sus obras, se encuentran los de «tragedias domésticas», de «épicas cotidianas», de juego escénico o de profunda crítica social. El autor conoce perfectamente toda esa letanía, o, si se prefiere, toda esa variedad terminológica utilizada para explicar la diversidad temática y la complejidad formal de sus obras y, con suma finura, nos ofrece siempre una mirada interpretativa y antiépica de las personas y de las cosas.

Ante esa mirada, mi hipótesis abductiva me lleva a conjeturar que el escepticismo crítico del autor es fruto de un profundo antifundamentalismo y antidogmatismo. Es difícil encontrar en sus piezas juicios categóricos, y raramente las cosas presentan sólo una de sus caras. La instancia enunciativa del autor nos lleva a la voz de los propios personajes, y éstos, se llamen Raúl, Mario, Berta o Bea, se pronuncian de forma distinta respecto a la violencia o al racismo. Ello no quiere decir que el discurso del autor se muestre indiferente ante las lacras de la sociedad. Lo que sucede es que estas conductas execrables no las considera sólo exclusivas de un grupo determinado, por muy marginal o antisocial que sea. Nadie está exento de su cuota de responsabilidad.

Alonso de Santos nos muestra en todas sus piezas - y en Salvajes lo subraya especialmente - que cada asunto es susceptible de ser abordado con varios registros y que las diversas intenciones pueden ser declaradas con múltiples discursos. Los temas trágicos pueden ser abordados desde la perspectiva del humor, a pesar de que las preceptivas ilustradas, dominadas por un exceso de racionalismo, nos digan lo contrario.

Alonso de Santos construye su universo dramático no desde el plano de la superioridad, sino desde el de la igualdad de los discursos artístico- 
ficcionales y los discursos filosófico-racionales, y Carlos Molinero sigue aquí con fidelidad este planteamiento metodológico.

Con «gramática jocosa», por utilizar una expresión de Rabelais, el dramaturgo estructura sus instancias enunciativas y diseña el contexto pragmático. Tales procedimientos son empleados igualmente en el film de Carlos Molinero, que, frente a la estética clásica — caracterizada en lo esencial por la unidad y la armonía-, prefiere unos modos expresivos que privilegien lo asimétrico, lo oximorónico y lo heterogéneo. Por ello, la representación y la interpretación del realizador no deben considerarse menos respetables, sino más bien como uno de los modos más pertinentes para marcar las diferencias, las contradicciones, las antítesis; en resumen, las distintas fuerzas en conflicto.

A Carlos Molinero, además de los mensajes pragmáticos, probablemente le llamó la atención la diversificación de la instancia enunciativa en varias voces, que, aparte de las posibilidades que ofrece a la expresión fílmica, estaba perfectamente en consonancia con el discurso antimonológico y antiautoritario del realizador. Sobre la naturaleza del enunciador en el cine las posturas no son coincidentes: frente a los que subrayan su importancia como Gaudreault (1988) y Casetti (1989), otros, como Bordwell (1996), insisten en la relativización del mismo. En cualquier caso el sujeto enunciador opera siempre como aparato simbólico y elemento organizador de todos los procesos semióticos que se desarrollan en el film.

En cuanto a los personajes, en la obra teatral, la pareja integrada por Berta y el Comisario son dos personas mayores - tienen «unos sesenta años»-que representan la voz de la experiencia y ven con pasmo y con terror cómo los jóvenes destrozan cuanto encuentran a su paso y se destruyen a sí mismos sin entender por qué.

En la película, Carlos Molinero les ha rebajado la edad a los personajes, representados por Marisa Paredes e Imanol Arias, y los muestra casi tan perdidos en la vida como los jóvenes. A su vez, los arquetipos de los salvajes, o, si se quiere, los personajes especializados en la función de malignos, no están desprovistos de experiencia vital en el film, y sus rasgos negativos, si no son suavizados, tampoco merecen el estigma. Coinciden en cierto modo con los mayores en la búsqueda de algo que no saben exactamente lo que es. Conocen lo más inmediato, como conocen algunas de sus aspiraciones y de sus sentimientos más próximos: Berta es 
«la rubia de ojos tristes», que se enamora del policía, y el sobrino pequeño quiere ser paracaidista. Pero no termina ahí la cosa.

En la obra teatral la acción se condensa en dos espacios cerrados: el de una casa de clase media, en el que pueden, a la vez, distinguirse, el salóncomedor y la terraza, y el de la comisaría.

La película, nada más comenzar, ya señala varios espacios interrelacionados y dinámicos. El texto literario contemporáneo ha devuelto al espacio el lugar que ya ocupó en la literatura y en el pensamiento clásicos, operación a la que no han resultado ajenas las tesis de Kant ([1781] 1994), Cassirer ([1923. 1925 y 1929], 1971-1976) y las teorizaciones de Maurice Blanchot (1955), Gaston Bachelard (1965), Gerard Genette (1969) y Iuri Lotman (1978), entre otros. A la consolidación de este nuevo estatuto del vector espacial han contribuido eficazmente los discursos escénicos y cinematográficos (cf. José Castillo, ed., 2002). Todos los elementos que intervienen en las representaciones teatrales y fílmicas encuentran en el espacio su valor sémico (Ubersfeld, 1981: 53). Los ámbitos cerrados de la comisaría, del salón-comedor y de la terraza en la obra de Alonso de Santos alcanzan su complementación en otros espacios aludidos, como la cárcel, el ambulatorio y la calle, en los que se desarrolla - sobre todo en la calle - una parte importante de la acción. Berta le recuerda a su sobrina Bea que viene de la cárcel, no de un balneario de tomar aguas y que «lo único bueno que tiene estar allí metida es que aprendes a convivir con todas las desgracias de este mundo». Al ambulatorio acude el Comisario a que le pongan sus inyecciones, asunto que funciona en la obra como elemento distanciador y con una evidente carga irónica. La calle, a su vez, es el escenario privilegiado de Mario y Raúl, un espacio considerado por los «cabezas paradas» como algo de su propiedad y no como un ámbito de convivencia.

Frente a lo cerrado de los espacios escénicos, los fílmicos son prácticamente ilimitados e infinitos. En la película de Carlos Molinero ya desde sus comienzos contemplamos lo abierto de las costas mediterráneas. A sus playas, acuciados por la esperanza de una vida mejor, llegan oleadas de «ilegales» del continente africano. A los duros y desolados escenarios de lo urbano lindante con el mar acuden también Berta, la atractiva enfermera de aspecto frágil y de carácter fuerte, y el policía Eduardo, cargado de tanta insatisfacción y soledad como la mujer. El escenario del puerto acentúa ese carácter de fugacidad al que se ha hecho referencia. En este 
territorio las cosas y las personas entran y salen; todo es pasajero y fugaz, y el único elemento que parece tener cierta perdurabilidad es el ritmo de los embates y de los golpes repetidos del mar contra el cemento.

En los códigos sonoros, los elementos musicales no adquieren un especial espesor ni en el discurso teatral ni en el fílmico. En la obra de teatro «suena un casete con música «ska» muy alta» en la escena tercera. En film de Carlos Molinero oímos una canción de muy diverso signo. En toda la película, aparte del diálogo de los personajes, el elemento sonoro viene proporcionado por el sonido ambiente. No recurre por tanto a la utilización over de la música, como acompañamiento de la escena, ni tampoco como recurso «que concluye in crescendo una secuencia y acentúa el corte con respecto a la secuencia siguiente» (Casett-Di Chio, 1991: 103). Sólo en el momento en el que están bailando Berta y Eduardo, la música aparece implicada directamente en la acción. Este rasgo de buscada contención en una película tan cargada de intensidad debe de responder, entre otros motivos, al propósito del realizador de inscribir su discurso fílmico en el movimiento del Dogma. Las influencias de esta escuela parecen evidentes, de la misma forma que no resultan ajenos ciertos modos expresivos de John Cassavetes, de À bout de souffle, de Jean-Luc Godard, y de El odio, de Mathieu Kassovitz.

Descartada la música para marcar la transición de una secuencia a otra, el director recurre a procedimientos muy diversos, entre ellos, el de iconos prosaicos de la sociedad industrial, como los camiones que van y vienen, transitando con gran celeridad. Al final comprenderemos, que, aparte de esta función articuladora de la sintaxis fílmica, los camiones encierran elementos portadores de profunda significación.

Como espectadores, nos incumbe el papel de interpretar esos mensajes. Y desde la postura del receptor, es desde la que cobra especial relieve esa representación reflexiva, abductiva y antiépica, a la que se ha hecho referencia. Para su interpretación podría igualmente recurrirse a la teoría de los diversos simulacros de Jean Baudrillard (1976).

Con el concepto de hipótesis conjetural o abductiva no estamos defendiendo los presupuestos metodológicos o antimetodológicos de Feyerabend (1974), ni el carácter ilimitado de la semiosis, ni las derivas infinitas del significado ante las cuales ha mostrado recelos el propio Umberto Eco (1992). 
No hay que perder de vista, por otra parte, que el concepto de relativización del significado, producido en la reflexión filosófica a partir de las tesis de Heidegger y, sobre todo, de las de Nietzsche, se acentuó con las lecturas hermenéuticas y deconstruccionistas. En la base de las mismas está presente la crisis de la referencialidad del lenguaje, la sospecha de que el lenguaje no es un sistema que describe el mundo, sino que lo crea. En este sentido, el deconstruccionismo de Derrida reacciona en contra de la tentativa de una gramática de la significación, porque las obras se transforman en objetos móviles, inservibles para el dogmatismo crítico (Bernárdez, 2000: 16). Pero la crítica contemporánea dista mucho de ser deconstruccionista. Ya se ha visto cómo el propio Eco (1992) matizaba sus tesis sobre la posibilidad de una semiosis ilimitada.

Sin embargo, esa relativización del significado en el campo filosófico, coincidiendo con la crisis de las poéticas textuales en el de la crítica literaria, ha movilizado las diversas estrategias pragmáticas, entre ellas de forma muy especial, la función del receptor o espectador. En relación con el espectador, el film, como ya señala Metz (1979) — y la película Salvajes es buen ejemplo de ello-, se da a ver, instituye su propia finalidad, su propio destino, la meta que intenta alcanzar. Pero el espectador dispone de su enciclopedia, y de acuerdo con ella lo interpreta.

La reflexibilidad fílmica de Salvajes está ya propiciada por la riqueza expresiva del texto de Alonso de Santos, que intenta superar en su escritura la transposición directa de la realidad, al estilo de lo que hacían los escritores del «espejo a lo largo del camino». La escritura dramática en este caso está ya evidenciando el potencial reflexivo de la ficción, que luego se aprovechará en el discurso cinematográfico. Aquí los textos teatrales y fílmicos no dejan de ser espejos, pero se trata de espejos que modifican y transfiguran la representación. Estas ideas que defienden Danto (1983) y otros teóricos para las distintas prácticas artísticas ya están presentes en la dramaturgia valleinclanesca y en el símil de los espejos del callejón de Álvarez Gato. En nuestro caso, sin embargo, los modos expresionistas son sustituidos por fórmulas aparentemente más contenidas, pero igualmente distanciadas del puro mimetismo referencial.

A Molinero no le preocupa declarar expresamente en muchos casos la distinción entre mundos ficcionales y reales, y no precisamente por un menosprecio de la ficción ni por una baja estima del referente, sino por un compromiso fuerte con la realidad y con el arte. 
La película de Carlos Molinero - y aquí sí que las coincidencias con la obra de Alonso de Santos resultan más evidentes - se erige en un rechazo del maniqueísmo moral, en una defensa de la perplejidad ética y de una posición antropológica multicultural.

\section{REFERENCIAS BIBLIOGRÁFICAS}

Alonso de Santos, J. L. (2001). Yonquis y yanquis. Salvajes (Dos tragedias cotidianas), ed. de César Oliva. Madrid: Castalia.

Amorós, A. (1992). Introducción a su edición de El álbum familiar. Bajarse al moro, de José Luis Alonso de Santos. Madrid: EspasaCalpe, col. «Austral».

_ (1995). Introducción a su edición de La estanquera de Vallecas. La sombra del Tenorio. Madrid: Castalia.

Bachelard, G. (1965). Poética del espacio. México: Fondo de Cultura Económica.

BAUdrillard, J. (1976). L'Échange symbolique et la Mort. NRF Sciencies Humanes. París: Gallimard.

Bernárdez, A. (2000). El sueño de Hermes (La recepción en la esfera comunicativa). Madrid: Huerga \& Fierro.

Blanchot, M. (1955). L'espace litteraire. París: Gallimard.

Bobes, M. C. (1987). Semiología de la obra dramática. Madrid: Taurus.

Bordwell, D. (1985). La narración en el cine de ficción. Barcelona: Paidós.

BRunetTA, G. P. (1970). Forma e parole nel cinema. Padua: Liviana.

- (1987). Nacimiento del relato cinematográfico. Madrid: Cátedra.

CASETti, F. (1989). El film y su espectador. Madrid: Cátedra.

Casetti, F. y Di Chio, F. (1991). Cómo analizar un film. Barcelona: Paidós. 
CASSIRER, E. ([1923, 1925 y 1929], 1971-1976). Filosofía de las formas simbólicas. México: Fondo de Cultura Económica.

DANTO, A. (1983). «Some refections on Literature and Life». En Heinrich, D. -Iser, W. Funktionen des Fiktiven, 529-536. Munich: Fink.

ECO, U. (1992). Los límites de la interpretación. Barcelona: Lumen.

Feyerabend, P. K. (1974). Contra el método. Barcelona: Ariel.

Genette, G. (1969). Figures, II. París: Seuil.

Gaudreault, A. (1988). Du littérature au filmique: système du récit. París: Klincksieck.

Gutiérrez Carbajo, F. (1993). Cine y literatura. Madrid: Universidad Nacional de Educación a Distancia.

- (2001). «Versiones fílmicas de Bajarse al moro, de José Luis Alonso de Santos y de La mirada del hombre oscuro, de Ignacio del Moral». Anales de Literatura Española Contemporánea. «Teatro y Cine», volume 26, Isue I, 213-237.

- (2003). Introducción a Alonso de Santos. Que siga la comedia. Texto integro de «La comedia de Carla y Luisa». Madrid: Centro Cultural de la Villa (Ayuntamiento de Madrid).

Kant, I. ([1781] 1994). Crítica de la razón pura, trad. P. Ribas. Madrid: Alfaguara.

Lotman, I. (1978). Estructura del texto artístico. Madrid: Istmo.

Medina VicARIO, M. (1994). Los géneros dramáticos en la obra teatral de José Luis Alonso de Santos. Madrid: Ediciones Libertarias y AAT.

Memmi, A. (1968). Dominated Man. Boston: Beacon Press.

Metz, C. ( 1979). El significante imaginario. Barcelona: Gustavo Gili.

Morris, C. (1946). Signs, Language and Behavior. New York: Prentice May.

Oliva, C. (1989). El teatro desde 1936. Madrid: Alhambra.

- (2001). Introducción a su edición de Yonquis y yanquis. Salvajes, de José Luis Alonso de Santos. Madrid: Castalia. 
PiÑERo, M. (2001). Introducción a su edición de Dígaselo con Valium, de José Luis Alonso de Santos. El Puerto de Santa María: Fundación «Pedro Muñoz Seca» y Hogar Sur, S. A.

Romera Castillo, J. (2002). Prólogo a Mis versiones de Plauto. «Anfitrión», «La dulce Cásina»y «Miles gloriosus», de José Luis Alonso de Santos. Madrid: Universidad Nacional de Educación a Distancia.

Romera Castillo, J. (ed.) (2002). Del teatro al cine y la televisión en la segunda mitad del siglo XX. Madrid: Visor Libros.

SAntolaria, C. (1995). «El demonio, el mundo y mi carne, de José Luis Alonso de Santos: el eslabón que cierra una trilogía». Teatro. Revista de Estudios Teatrales 6-7. 217-247.

Ubersfeld, A. (1981). L’École du spectateur. Lire le théâtre, 2. París: Éd. Sociales.

— (1989). Semiótica teatral. Madrid: Cátedra. 